\title{
The Relation between Apolipoprotein E4 Genotype and Vascular Dementia
}

\author{
Tomader Taha Abdel Rahman ${ }^{*}$, Safia Mohamed Shehata ${ }^{2}$ \\ ${ }^{1}$ Geriatrics Medicine Department, Faculty of Medicine, Ain Shams University, Cairo, Egypt \\ ${ }^{2}$ Clinical Pathology Department, Ain Shams University Hospitals, Cairo, Egypt \\ Email: ${ }^{*}$ tomelhagyn@hotmail.com
}

Received 14 May 2014; revised 17 June 2014; accepted 1 July 2014

Copyright (C) 2014 by authors and Scientific Research Publishing Inc.

This work is licensed under the Creative Commons Attribution International License (CC BY). http://creativecommons.org/licenses/by/4.0/

(c) (i) Open Access

\section{Abstract}

Most studies investigating genetics of dementia have focused on Alzheimer's disease, but little is known about the genetics of vascular dementia (VD). The aim of this study was to identify the association between Apolipoprotein E4 (Apo E4) genotype and VD in cerebrally infarcted patients. The study was conducted on 100 patients with cerebral infarction: 50 had VD (cases) and 50 didn't have dementia (controls). Diagnosis of VD was based on Mini-Mental State Examination, Cambridge Cognitive Examination (CAMCOG), the Diagnostic and Statistical Manual of Mental Disorders 4th edition criteria for the diagnosis of VD (DSM-IV), Hachinski Ischemic Score, and computed tomography of the brain (CT brain). Apo E4 allele was assessed through DNA genotyping. The study showed that hypertension $(p=0.027,0 R=4.71)$, diabetes mellitus $(p=0.003,0 R=6.05)$ and Apo E4 allele $(p=0.017, O R=13.39)$ were the independent risk factors of VD among studied participants. The study concluded that cerebrally infarcted patients with Apo E4 genotype are at high risk of developing VD.

\section{Keywords}

Apolipoprotein E4, Cerebral Infarction, Genetics, Vascular Dementia

\section{Introduction}

Vascular dementia (VD) is the second most common type of dementia, accounting for approximately $15 \%$ to $20 \%$ of all cases of dementia [1]. VD is defined as the loss of cognitive function resulting from ischemic or hemorrhagic brain lesions as a result of cerebrovascular disease [2]. Most studies that investigated the genetics of dementia have focused on Alzheimer's disease, the most common type of dementia, [3] but little is known about the genetics of VD [4].

\footnotetext{
${ }^{*}$ Corresponding author.
}

How to cite this paper: Rahman, T.T.A. and Shehata, S.M. (2014) The Relation between Apolipoprotein E4 Genotype and Vascular Dementia. Advances in Aging Research, 3, 208-215. http://dx.doi.org/10.4236/aar.2014.33029 
Apolipoprotein E (Apo E) gene is mapped to chromosome 19 in a cluster with Apolipoprotein C1 and Apolipoprotein C2. Apo E is polymorphic with three major isoforms: Apo E2, Apo E3 and Apo E4. Although these allelic forms differ from each other by only one or two amino acids, these differences alter Apo E function. Regarding Apo E4 allele, it has been implicated in the development of intracranial atherosclerosis and ischemic stroke [5]. However, it remains controversial regarding the association between Apo E4 genotype and the risk of developing VD [6].

Baum et al. [7] and Chuang et al. [8] found an association between Apo E4 polymorphism and VD. On the other hand, Chuang et al. [9] didn’t find this association.

So the aim of this study was to identify the association between Apo E4 genotype and VD in cerebrally infarcted patients.

\section{Methods}

\subsection{Study Design}

Case control study.

\subsection{Study Settings and Study Participants}

The study was carried out at Ain Shams University hospitals, Egypt. One hundred elderly patients with cerebrovascular infarction agreed to participate in this study, 50 have VD (cases) and 50 don't have dementia (controls). Informed consent was taken from each participant, or participant's proxy, and full confidentiality of the data collected was ensured to all participants.

\subsection{Clinical Assessment}

All participants were subjected to complete medical history taking (including history of new onset dementia within 3 months of a stroke, history of hypertension, hypercholesterolemia, diabetes mellitus, cardiovascular diseases), complete examination (including neurological examination, assessment of Body Mass Index (BMI)) [10], and Geriatric Depression Scale-15 (GDS-15)] [11].

Hypertension was defined as a setting blood pressure $\geq 140 / 90 \mathrm{mmHg}$ [12], or if hypertension had been verified earlier. Diabetes mellitus was defined as fasting blood glucose $\geq 126 \mathrm{mg} / \mathrm{dl} \&$ postprandial blood glucose $\geq 200$ $\mathrm{mg} / \mathrm{dl}$ [13], or if diabetes mellitus had been verified earlier. Hypercholesterolemia was defined as a total cholesterol level $\geq 200 \mathrm{mg} / \mathrm{dl}$. Hyper triglyceridemia was defined as a total triglycerides (TG) $\geq 150 \mathrm{mg} / \mathrm{dl}$. High low density lipoprotein-cholesterol (LDL-C) level was defined as a total LDL-C level $\geq 130 \mathrm{mg} / \mathrm{dl}$. Low high density lipoprotein-cholesterol (HDL-C) level was defined as a HDL-C level $<40 \mathrm{mg} / \mathrm{dl}$ in men and $<50 \mathrm{mg} / \mathrm{dl}$ in women [14], or if hyperlipidemia had been verified earlier.

\subsection{Cognitive Assessment}

Mini mental state examination was used for cognitive assessment. Score $\geq 26$ indicates normal cognitive function and score $<23$ indicates dementia [15]. The Cambridge Cognitive Examination (CAMCOG) [16] is a diagnostic test for cognitive function. A score of 90 or more indicates normality, $78-89$ is an indication of mild cognitive impairment (MCI), and a score lower than 78 is diagnostic for dementia. Subjects were included in the current study if they were cognitively normal (controls) or demented (cases).

\subsection{Diagnosis of VD}

Diagnosis of VD was based on the Diagnostic and Statistical Manual of Mental Disorders 4th edition criteria for diagnosis of VD (DSM-IV) [17], Hachinski Ischemic Score $\geq 7$ [18], and the presence of one or more areas of infarction; diagnosed by brain computed tomography (CT).

\subsection{Apo E4 Genotyping}

Two cm of venous blood sample was drawn from each participant on EDTA tube. Genotyping at the ApoE Locus from the collected blood samples was performed by isolation of high-molecular weight genomic DNA using the modified salting-out protocol [19]. Polymerase chain reaction (PCR) amplification was performed using gene 
specific primers (forward: 5'-TAA GCT TGG CAC GGC TGT CCA AGG A-3', reverse: 5'-ACA GAA TTC GCC CCG GCC TGG TAC ACT GCC-3') followed by restriction enzyme cleavage of the PCR products with the HhaI enzyme to generate allele-discriminating DNA fragments [20]. Briefly, the 3 alleles E2, E3 and E4 were defined by the presence of either $C$ or $T$ nucleotides at codons 112 and 158 in the 4th exon of the ApoE gene by PCR restriction fragment length polymorphism method. This was determined by a laboratory specialist blind to the participants' characteristics, and the results were categorized according to the presence or absence of Apo E4 genotype.

\subsection{Laboratory Assessment of Serum Lipids and Blood Sugar}

Fourteen hours fasting venous sample was taken for assessment of serum lipids and fasting blood sugar and another two hours postprandial venous sample was drawn for assessment of postprandial blood sugar. Samples were allowed to clot for no more than 30 minutes, and then centrifuged. Serum lipids (Total cholesterol, TG, LDL-C, HDL-C) and blood sugar concentrations were measured enzymatically (Boehringer Mannheim, Germany) using standard laboratory methods in an automatic analyzer (Synchron CX 5) at the central laboratories of Ain Shams University Hospitals.

\subsection{Exclusion Criteria}

Patients with mild cognitive impairment, Alzheimer's dementia, mixed dementia, any neurological or cognitive disorders, other than what caused by the recent infarction, were excluded.

\subsection{Data Management and Statistical Analysis}

Data was analyzed using the $15^{\text {th }}$ version of SPSS (Statistical Package for Social Science). The results were presented as mean \pm SD for normally distributed data. Continuous data were compared between groups using unpaired t-test for normally distributed variables. Categorical data were compared between groups by $\chi^{2}$ test. Multiple logistic regression analysis was used to detect the independent risk factors of VD among studied participants. Significance was taken at 5\% level.

\section{Results}

The studied sample included 36 males; (18 cases and 18 controls) and 64 females; (32 cases and 32 controls). Both cases and controls were cross matched regarding age and sex with mean age of cases and controls $68.0 \pm$ 5.5 and $67.4 \pm 5.7$ respectively. There were significant differences between cases and controls regarding level of education ( $p=<0.001)$, BMI $(p=0.010)$, hypertension $(p=0.033)$, duration of hypertension $(p=0.027)$, DM $(p=$ 0.026), duration of diabetes $(\mathrm{p}=0.007)$, high LDL-C $(\mathrm{p}=0.023)$, low HDL-C $(\mathrm{p}=0.049)$ and Apo E4 allele $(\mathrm{p}=$ 0.001) (Table 1).

There was a significant difference between the studied groups regarding the type of ischemic infarction: single infarction, lacunar infarctions or multiple large infarctions $(\mathrm{p}=<0.001)$. When we re-categorized the studied participants into participants have lacunar infarctions and others have non lacunar infarctions, a significant association between the presence of lacunar infarctions and VD was also detected $(p=0.002)$ (Table 2).

Studying the association between infarction site and VD revealed non-significant association between VD and different infarction sites: parietal lobe infarction, temporal lobe infarction, frontal lobe infarction, capsular infarction, thalamic-basal ganglia infarction or periventricular infarctions $(p=0.692)$ (Table 3). When we re-categorized the studied participants into participants have cortical and others have subcortical infarction, also the result was non-significant ( $\mathrm{p}=0.532$ ).

Multiple logistic regression analyses revealed that hypertension $(\mathrm{p}=0.027, \mathrm{OR}=4.71)$, diabetes mellitus $(\mathrm{p}=$ 0.003, OR $=6.05)$ and Apo E4 allele ( $\mathrm{p}=0.017$, OR = 13.39) were the independent risk factors of VD among studied participants (Table 4).

\section{Discussion}

In literature, there has been a matter of controversy about the association between Apo E4 allele and the risk of developing VD. Some studies reported positive associations [7] [21] [22], while others showed no associations 
Table 1. Comparison between cases and controls regarding demographic and clinical data.

\begin{tabular}{|c|c|c|c|}
\hline & Cases $(n=50)$ & Controls $(n=50)$ & $P$ value \\
\hline Age (years) & $68.0 \pm 5.5$ & $67.4 \pm 5.7$ & 0.801 \\
\hline Female gender & $32(50 \%)$ & 32 (50\%) & 1.000 \\
\hline \multicolumn{4}{|l|}{ Education } \\
\hline Illiterate & $22(71.0 \%)$ & $9(29.0 \%)$ & \multirow{5}{*}{$<0.001$} \\
\hline Primary & $14(66.7 \%)$ & $7(33.3 \%)$ & \\
\hline Preparatory & $4(25.0 \%)$ & $12(75.0 \%)$ & \\
\hline Secondary & $5(50 \%)$ & $5(50 \%)$ & \\
\hline High education & $5(22.7 \%)$ & 17 (77.3\%) & \\
\hline Body mass index $\left(\mathrm{kg} / \mathrm{m}^{2}\right)($ Mean $\pm \mathrm{SD})$ & $25.0 \pm 7.7$ & $28.4 \pm 7.5$ & 0.010 \\
\hline Family history of VD & $12(75.0 \%)$ & $4(25.0 \%)$ & 0.060 \\
\hline Hypertension & 32 (59.3\%) & $22(40.7 \%)$ & 0.033 \\
\hline Hypertension duration (years) & $18.3 \pm 8.9$ & $14.6 \pm 9.9$ & 0.027 \\
\hline Diabetes mellitus & $25(62.5 \%)$ & 15 (37.5\%) & 0.026 \\
\hline DM duration (years) & $23.8 \pm 10.9$ & $15.1 \pm 11.3$ & 0.007 \\
\hline IHD & $6(50.0 \%)$ & $6(50.0 \%)$ & 0.978 \\
\hline Heart failure & $8(66.7 \%)$ & $4(33.3 \%)$ & 0.202 \\
\hline Atrial fibrillation & $5(71.4 \%)$ & $2(28.6 \%)$ & 0.158 \\
\hline Geriatric depression scale-15 (Mean \pm SD) & $1.85 \pm 0.55$ & $1.72 \pm 0.59$ & 0.790 \\
\hline High cholesterol & $7(63.6 \%)$ & $4(36.4 \%)$ & 0.176 \\
\hline High TG & $11(55.0 \%)$ & $9(45.0 \%)$ & 0.541 \\
\hline High LDL-C & $18(69.2 \%)$ & $8(30.8 \%)$ & 0.023 \\
\hline Low HDL-C & $22(62.9 \%)$ & 13 (37.1\%) & 0.049 \\
\hline Apo E4 allele & $22(75.9 \%)$ & $7(24.1 \%)$ & 0.001 \\
\hline
\end{tabular}

Table 2. Association between type of ischemic infarction and vascular dementia.

\begin{tabular}{cccc}
\hline & Cases N (\%) & Controls N (\%) & P value \\
\hline Lacunar infarctions & $42(61.8 \%)$ & $26(38.2 \%)$ & 0.002 \\
Non lacunar infarctions & $8(25.0 \%)$ & $24(75.0 \%)$ & \\
\hline
\end{tabular}

Table 3. The association between cerebral infarction site and vascular dementia.

\begin{tabular}{ccc}
\hline Site of cerebral infarction & Cases N (\%) & Controls N (\%) \\
\hline Parietal & $14(53.8 \%)$ & $12(46.2 \%)$ \\
Temporal & $9(47.4 \%)$ & $10(52.6 \%)$ \\
Frontal & $3(60.0 \%)$ & $2(40.0 \%)$ \\
Capsular & $13(54.2 \%)$ & $11(45.8 \%)$ \\
Thalamic-Basal ganglia & $14(60.9 \%)$ & $9(39.1 \%)$ \\
Periventricular & $13(48.1 \%)$ & $14(51.9 \%)$ \\
\hline
\end{tabular}


Table 4. Multivariate logistic regression analysis to detect the independent risk factors of vascular dementia.

\begin{tabular}{|c|c|c|c|c|}
\hline & \multirow{2}{*}{$P$ value } & \multirow{2}{*}{ OR } & \multicolumn{2}{|c|}{$95.0 \% \mathrm{CI}$} \\
\hline & & & Lower & Upper \\
\hline Hypertension & 0.027 & 4.71 & 1.19 & 18.57 \\
\hline Diabetes mellitus & 0.003 & 6.05 & 1.87 & 19.54 \\
\hline Apo E4 & 0.017 & 13.39 & 1.60 & 111.83 \\
\hline Education level (illiterate) & 0.168 & 1.07 & 0.97 & 1.17 \\
\hline Body mass index $\leq 25\left(\mathrm{~kg} / \mathrm{m}^{2}\right)$ & 0.602 & 1.36 & 0.43 & 4.34 \\
\hline High LDL-C & 0.839 & 1.16 & 0.27 & 4.94 \\
\hline Low HDL-C & 0.284 & 1.36 & 0.78 & 2.39 \\
\hline Constant & 0.055 & 0.00 & & \\
\hline
\end{tabular}

OR (odds ratio), CI (confidence interval).

\section{[9] [23] [24].}

The present study revealed that participants with Apo E4 genotype were 13.4 times more likely to develop VD than those with no Apo E4 genotype. This relation may be due to the significant increase in carotid atherosclerosis, carotid plaques [25] and the greater decline in cerebral blood flow previously reported among carriers of this genotype [26].

As well, Apo E4 (relative to Apo E3 and E2) may be deficient in delivery of essential lipids for maintaining synaptic plasticity. This may be responsible for altering neuronal circuitry that eventually leads to cognitive disorders [27].

While, previous study reported that the effect of Apo E4 on VD may be mediated by dyslipidemia [28], this study reported that the effect of Apo E4 allele on VD is not mediated by dyslipidemia. If so, the association between Apo E4 and VD might be expected to attenuate after adjusting for dyslipidemia which didn't happen in this study. This finding is consistent with Prince and colleagues [29].

This study detected a significant association between lacunar infarctions and VD ( $p=0.002)$. Lacunar infarctions cause white matter tract disruption and disconnection of cortical-subcortical and cortical-cortical connections, underlying complex networks associated with cognitive control mechanisms and efficient information processing, leading to VD [30] [31]. This comes in adherence to Thong and colleagues [32] who reported that lacunar infarctions were significantly associated with VD supporting the fact that VD has common small vessel pathology.

Regarding the site of ischemic infarction, no one can ignore that strategic regions correspond to limbic and paralimbic structures and related circuits, which underpin cognitive functions; strokes in these eloquent sites produce pictures of VD [33]. The non-significant relation between infarction site and VD detected in this study may be due to the use of CT brain in detection of infarction site. In spite of that CT scan is one of the first tests done in a stroke diagnosis, Magnetic resonance imaging (MRI) is preferred over CT brain in stroke site evaluation because of multiple planes and sequences are needed to assess various regions, commonly affected in VD, such as amygdala, hippocampus, the prefrontal cortex, basal ganglia, thalamus and periventricular area [33] [34].

The current study showed that hypertension was an independent risk factor of VD $(p=0.027$, OR $=4.71)$. Hypertension can affect arteries, arterioles, and capillaries in various patterns and degrees in the brain. As well it may be associated with large and small infarcts, in isolated or diffuse patterns, causing VD [35].

Regarding the relation between DM and VD, this study revealed that diabetic patients were more likely to develop VD than those who have no DM ( $\mathrm{p}=0.003$, OR $=6.05)$. This agrees with Mayeda and colleagues [36] and it can be attributed primarily to diabetic vascular brain lesions [2].

Longer DM duration was significantly associated with VD $(p=0.007)$. This agrees with Tolppanen and colleagues [37].

There was a significant association between high LDL-C and VD. Much evidence suggests that increased 
LDL-C may lead to high susceptibility to oxidative stress. Brain is particularly vulnerable to this oxidative stress and lipid damage because of its high content of polyunsaturated fatty acids [38].

Regarding the significant association between low HDL-C level and VD, it may be linked to small vessel disease through the role of HDL-C in the removal of excess cholesterol from the subendothelial space of cerebral microvessels [39].

In our study we found that the mean BMI was significantly higher in the controls group (28.4 \pm 7.5$)$ than in the demented group $(25.0 \pm 7.7)$. This result was consistent with Huseyin and colleagues [40]. This relation may be a bidirectional relation; poor nutritional intake may be associated with deficiency of micronutrients, such as antioxidant vitamins (A, C, and E), and zinc [41], leading to changes in brain vasculature[42] , as well as in demented patients, low BMI may be developed as a consequence of dementia [43] [44].

Regarding education, Chaudhari and colleagues [44] reported that lower educational status was significantly associated with post stroke VD. This is consistent with the finding of this study $(\mathrm{p}<0.001)$.

Jack [45] stated that there is a strong association between VD and cardiac diseases including atrial fibrillation, heart failure and coronary artery disease. In this study, the non-significant association may be due to the small sample size of participants with cardiac diseases.

\section{Study Limitations}

The limitations of the current study were the relatively small sample size and inability to use MRI in detecting the relation between infarction site and VD due to its high cost.

\section{Conclusion}

Cerebrally infracted patients with Apo E4 genotype, hypertension, or DM are at high risk of developing VD. These results highlight the need for targeting those patients for early detection and prompt treatment of VD.

\section{Disclosure Statement}

The authors declare no conflict of interest.

\section{Authors' Contributions}

Tomader Taha Abdel Rahman: study design, data collection, data analysis and writing the manuscript; Safia Mohamed Shehata: laboratory and genetic work.

\section{References}

[1] Ruitenberg, A., Ott, A., van Swieten, J.C., Hofman, A. and Breteler, M.M. (2001) Incidence of Dementia: Does Gender Make a Difference? Neurobiology of Aging, 22, 575-580. http://dx.doi.org/10.1016/S0197-4580(01)00231-7

[2] Román, G.C. (2002) Vascular Dementia Revisited: Diagnosis, Pathogenesis, Treatment, and Prevention. Medical Clinics of North America, 86, 477-499. http://dx.doi.org/10.1016/S0025-7125(02)00008-1

[3] Argyri, L., Dafnis, I., Theodossiou, T.A., Gantz, D., Stratikos, E. and Chroni, A. (2014 ) Molecular Basis for Increased Risk for Late-Onset Alzheimer Disease Due to the Naturally Occurring L28P Mutation in Apolipoprotein E4. The Journal of Biological Chemistry, 289, 12931-12945.

[4] Joutel, A., et al. (1996) Notch3 Mutations in CADASIL, a Hereditary Adult-Onset Condition Causing Stroke and Dementia. Nature, 383, 707-710. http://dx.doi.org/10.1038/383707a0

[5] Abboud, S., et al. (2008) Associations of Apolipoprotein E Gene with Ischemic Stroke and Intracranial Atherosclerosis. European Journal of Human Genetics, 16, 955-960. http://dx.doi.org/10.1038/ejhg.2008.27

[6] Yin, Y.-W., Li, J.-C., Wang, J.-Z., Li, B.-H., Pi, Y., Yang, Q.-W., Fang, C.-Q., Gao, C.-Y. and Zhang, L.-L. (2012) Association between Apolipoprotein E Gene Polymorphism and the Risk of Vascular Dementia: A Meta-Analysis. Neuroscience Letters, 514, 6-11. http://dx.doi.org/10.1016/j.neulet.2012.02.031

[7] Baum, L., Lam, L.C., Kwok, T., Lee, J., Chiu, H.F., Mok, V.C., Wong, A., Chen, X., Cheung, W.S., Pang, C.P., Ma, S.L., Tang, N.L., Wong, K.S. and Ng, H.K. (2006) Apolipoprotein E Epsilon 4 Allele Is Associated with Vascular Dementia. Dementia and Geriatric Cognitive Disorders, 22, 301-305. http://dx.doi.org/10.1159/000095246

[8] Chuang, Y.F., Hayden, K.M., Norton, M.C., Tschanz, J., Breitner, J.C.S., Welsh-Bohmer, K.A. and Zandi, P.P. (2010) 
Association between APOE Epsilon4 Allele and Vascular Dementia: The Cache County Study. Dementia and Geriatric Cognitive Disorders, 29, 248-253. http://dx.doi.org/10.1159/000285166

[9] Engelborghs, S., Dermaut, B., Goeman, J., Saerens, J., Marien, P., Pickut, B.A., Van den Broeck, M., Serneels, S., Cruts, M., Van Broeckhoven, C. and De Deyn, P.P. (2003) Prospective Belgian Study of Neurodegenerative and Vascular Dementia: APOE Genotype Effects. Journal of Neurology, Neurosurgery Psychiatry, 74, 1148-1151. http://dx.doi.org/10.1136/jnnp.74.8.1148

[10] World Health Organization (1995) Physical Status: The Use and Interpretation of Anthropometry: Report of a WHO Expert Committee. Technical report series 854, Geneva.

[11] Sheikh, J.A., Yesavage, J.A. (1986) Recent Finding and Development of a Shorter Version. In Brinn, T.L., Ed., Clinical Gerontology: A Guide to Assessment and Intervention, Hawarth Press, New York, 165-173.

[12] Guidelines Subcommittee, World Health Organization-International Society of Hypertension (1999) Guidelines for the Management of Hypertension. Journal of Hypertension, 17, 151-183.

[13] American Diabetes Association (2003) Screening for Type 2 Diabetes, Diabetic Care, 26, S21-S24.

[14] Third Report of the National Cholesterol Education Program (NCEP) (2001) Expert Panel on Detection, Evaluation, and Treatment of High Blood Cholesterol in Adults (Adult Treatment Panel III) Executive Summary. National Heart, Lung, and Blood Institute (NHLBI), National Institutes of Health.

[15] Folstein, M.F., Folstein, S.E. and McHugh, P.R. (1975) “Mini-Mental State” A Practical Method for Grading the Cognitive State of Patients for the Clinician. Journal of Psychiatric Research, 12, 189-198. http://dx.doi.org/10.1016/0022-3956(75)90026-6

[16] Williams, J.G., Huppert, F.A., Matthews, F.E. and Nickson, J. (2003) Performance and Normative Values of a Concise Neuropsychological Test (CAMCOG) in an Elderly Population Sample. International Journal of Geriatric Psychiatry, 18, 631-644.

[17] American Psychiatric Association (2000) Diagnostic and Statistical Manual of Mental Disorders. 4th Edition, Text Revision, American Psychiatric Association, Washington DC.

[18] Hachiniski Merck Manual of Geriatrics. 2nd Edition, 1995, 1156. Version Modified from Hachinski, V.C., Iliff, L.D., Phil, M., et al. (1975) Cerebral Blood Flow in Dementia. Archives of Neurology, 32, 632-637.

[19] Miller, S., Dykes, D. and Polesky, H. (1988) A Simple Salting out Procedure for Extracting DNA from Human Nucleated Cells. Nucleic Acids Research, 16, 1215. http://dx.doi.org/10.1093/nar/16.3.1215

[20] Wenham, P.R., Price, W.H. and Blundell, G. (1991) Apolipoprotein E Genotyping by One-Stage PCR. Lancet, 337, 1158-1159. http://dx.doi.org/10.1016/0140-6736(91)92823-K

[21] Davidson, Y., Gibbons, L., Purandare, N., Byrne, J., Hardicre, J., Wren, J., et al. (2006) Apolipoprotein E v4 Allele Frequency in Vascular Dementia. Dementia and Geriatric Cognitive Disorders, 22, 15-19. http://dx.doi.org/10.1159/000092960

[22] Yang, J., Feng, G., Zhang, J., Hui, Z., Breen, G., St Clair, D. and He, L. (2001) Is APOE Gene a Risk Factor for Vascular Dementia in Han Chinese? International Journal of Molecular Medicine, 7, 217-219.

[23] Kim, K.W., Youn, J.C., Han, M.K., Paik, N.J., Lee, T.J., Park, J.H., et al. (2008) Lack of Association between Apolipoprotein E Polymorphism and Vascular Dementia in Koreans. Journal of Geriatric Psychiatry and Neurology, 21, 12-17. http://dx.doi.org/10.1177/0891988707311028

[24] Lin, H.F., Lai, C.L., Tai, C.T., Lin, R.T. and Liu, C.K. (2004) Apolipoprotein E Polymorphism in Ischemic Cerebrovascular Diseases and Vascular Dementia Patients in Taiwan. Neuroepidemiology, 23, 129-134. http://dx.doi.org/10.1159/000075956

[25] Debette, S., Lambert, J.C., Gariépy, J., Fievet, N., Tzourio, C., Dartigues, J.F., Ritchie, K., Dupuy, A.M., Alpérovitch, A., Ducimetière, P., Amouyel, P. and Zureik, M. (2006) New Insight into the Association of Apolipoprotein E Genetic Variants with Carotid Plaques and Intima-Media Thickness. Stroke, 37, 2917-2923. http://dx.doi.org/10.1161/01.STR.0000249011.94055.00

[26] Thambisetty, M., Beason-Held, L.L., An, Y., Kraut, M., Nalls, M., Hernandez, D.G., et al. (2010) APOE $\varepsilon 4$ Genotype and Longitudinal Changes in Cerebral Blood Flow in Normal Aging. JAMA Neurology, 67, 93-98. http://dx.doi.org/10.1001/archneurol.2009.913

[27] Klein, R.C., Mace, B.E., Moore, S.D. and Sullivan, P.M. (2010) Progressive Loss of Synaptic Integrity in Human Apolipoprotein E4 Targeted Replacement Mice and Attenuation by Apolipoprotein E2. Neuroscience, 171, 1265-1272.

[28] Notkola, I.L., Sulkava, R., Pekkanen, J., Erkinjuntti, T., Ehnholm, C., Kivinen, P., Tuomilehto, J. and Nissinen, A. (1998) Serum Total Cholesterol, Apolipoprotein E Epsilon 4 Allele, and Alzheimer's Disease. Neuroepidemiology, 17, 14-20. http://dx.doi.org/10.1159/000026149

[29] Prince, M., Lovestone, S., Cervilla, J., Joels, S., Powell, J., Russ, C. and Mann, A. (2000) The Association between 
APOE and Dementia Does Not Seem to Be Mediated by Vascular Factors. Neurology, 54, 397-402. http://dx.doi.org/10.1212/WNL.54.2.397

[30] O’Sullivan, M., Jones, D.K., Summers, P.E., Morris, R.G., Williams, S.C. and Markus, H.S. (2001) Evidence for Cortical "Disconnection” as a Mechanism of Age-Related Cognitive Decline. Neurology, 57, 632-638. http://dx.doi.org/10.1212/WNL.57.4.632

[31] Pantoni, L. (2010) Cerebral Small Vessel Disease: From Pathogenesis and Clinical Characteristics to Therapeutic Challenges. Lancet Neurology, 9, 689-701. http://dx.doi.org/10.1016/S1474-4422(10)70104-6

[32] Thong, J.Y., Hilal, S., Wang, Y., Soon, H.W., Dong, Y., Collinson, S.L., Anh, T.T., Ikram, M.K., Wong, T.Y., Venketasubramanian, N., Chen, C. and Qiu, A. (2013) Association of Silent Lacunar Infarct with Brain Atrophy and Cognitive Impairment. Journal of Neurology, Neurosurgery, and Psychiatry, 84, 1219-1225.

[33] Lanna, M.E., Alves, C.E., Sudo, F.K., Alves, G., Valente, L., Moreira, D.M., Cavalcanti, J.L. and Engelhardt, E. (2012) Cognitive Disconnective Syndrome by Single Strategic Strokes in Vascular Dementia. Journal of the Neurological Sciences, 322, 176-183.

[34] Van Straaten, E.C.W., Scheltens, P.H. and Barkhof, F. (2004) MRI and CT in the Diagnosis of Vascular Dementia. Journal of the Neurological Sciences, 226, 9-12. http://dx.doi.org/10.1016/j.jns.2004.09.003

[35] Igase, M., Kohara, K. and Miki, T. (2012) The Association between Hypertension and Dementia in the Elderly. International Journal of Hypertension, 2012, Article ID: 320648. http://dx.doi.org/10.1155/2012/320648

[36] Mayeda, E.R., Haan, M.N., Kanaya, A.M., Yaffe, K. and Neuhaus, J. (2013) Type 2 Diabetes and 10-Year Risk of Dementia and Cognitive Impairment among Older Mexican Americans. Diabetes Care, 36, 2600-2606.

[37] Tolppanen, A.M., Lavikainen, P., Solomon, A., Kivipelto, M., Uusitupa, M., Soininen, H. and Hartikainen, S. (2013) History of Medically Treated Diabetes and Risk of Alzheimer Disease in a Nationwide Case-Control Study. Diabetes Care, 36, 2015-2019.

[38] Dantoine, T.F., Debord, J., Merle, L., Lacroix-Ramiandrisoa, H., Bourzeix, L. and Charmes, J.P. (2002) Paraoxonase 1 Activity: A New Vascular Marker of Dementia? Annals of the New York Academy of Sciences, 977, 96-101. http://dx.doi.org/10.1111/j.1749-6632.2002.tb04802.x

[39] Zuliani, G., Ble, A., Zanca, R., Munari, M.R., Zurlo, A., Vavalle, C., Atti, A.R. and Fellin, R. (2001) Lipoprotein Profile in Older Patients with Vascular Dementia and Alzheimer's Disease. BMC Geriatrics, 1, 5. http://dx.doi.org/10.1186/1471-2318-1-5

[40] Huseyin Doruk, Naharci, M.I., Bozoglu, E., Isik, A.T. and Kilic, S. (2010) The Relationship between Body Mass Index and Incidental Mild Cognitive Impairment, Alzheimer's Disease, and Vascular Dementia in Elderly. The Journal of Nutrition, Health \& Aging, 14, 834-838.

[41] Sánchez-Moreno, C., Jiménez-Escrig, A. and Martín, A. (2009) Stroke: Roles of B Vitamins, Homocysteine and Antioxidants. Nutrition Research Reviews, 22, 49-67. http://dx.doi.org/10.1017/S0954422409990023

[42] Chai, J., Chu, F.C.S., Chow, T.W. and Shum, N.C. (2008) Prevalence of Malnutrition and Its Risk Factors in Stroke Patients Residing in an Infirmary. Singapore Medical Journal, 49, 290-296.

[43] Mould, J. (2009) Nurses "Must” Control of the Nutritional Needs of Stroke Patients. British Journal of Nursing, 18, 1410-1414. http://dx.doi.org/10.12968/bjon.2009.18.22.45572

[44] Chaudhari, T.S., Verma, R., Garg, R.K., Singh, M.K., Malhotra, H.S. and Sharma, P.K. (2014) Clinico-Radiological Predictors of Vascular Cognitive Impairment (VCI) in Patients with Stroke: A Prospective Observational Study. Journal of the Neurological Sciences, 340, 150-158.

[45] Jack, C. (2012) Cardiovascular Risk Factors Promote Brain Hypoperfusion Leading to Cognitive Decline and Dementia. Cardiovascular Psychiatry and Neurology, 2012, Article ID: 367516. 
Scientific Research Publishing (SCIRP) is one of the largest Open Access journal publishers. It is currently publishing more than 200 open access, online, peer-reviewed journals covering a wide range of academic disciplines. SCIRP serves the worldwide academic communities and contributes to the progress and application of science with its publication.

Other selected journals from SCIRP are listed as below. Submit your manuscript to us via either submit@scirp.org or Online Submission Portal.
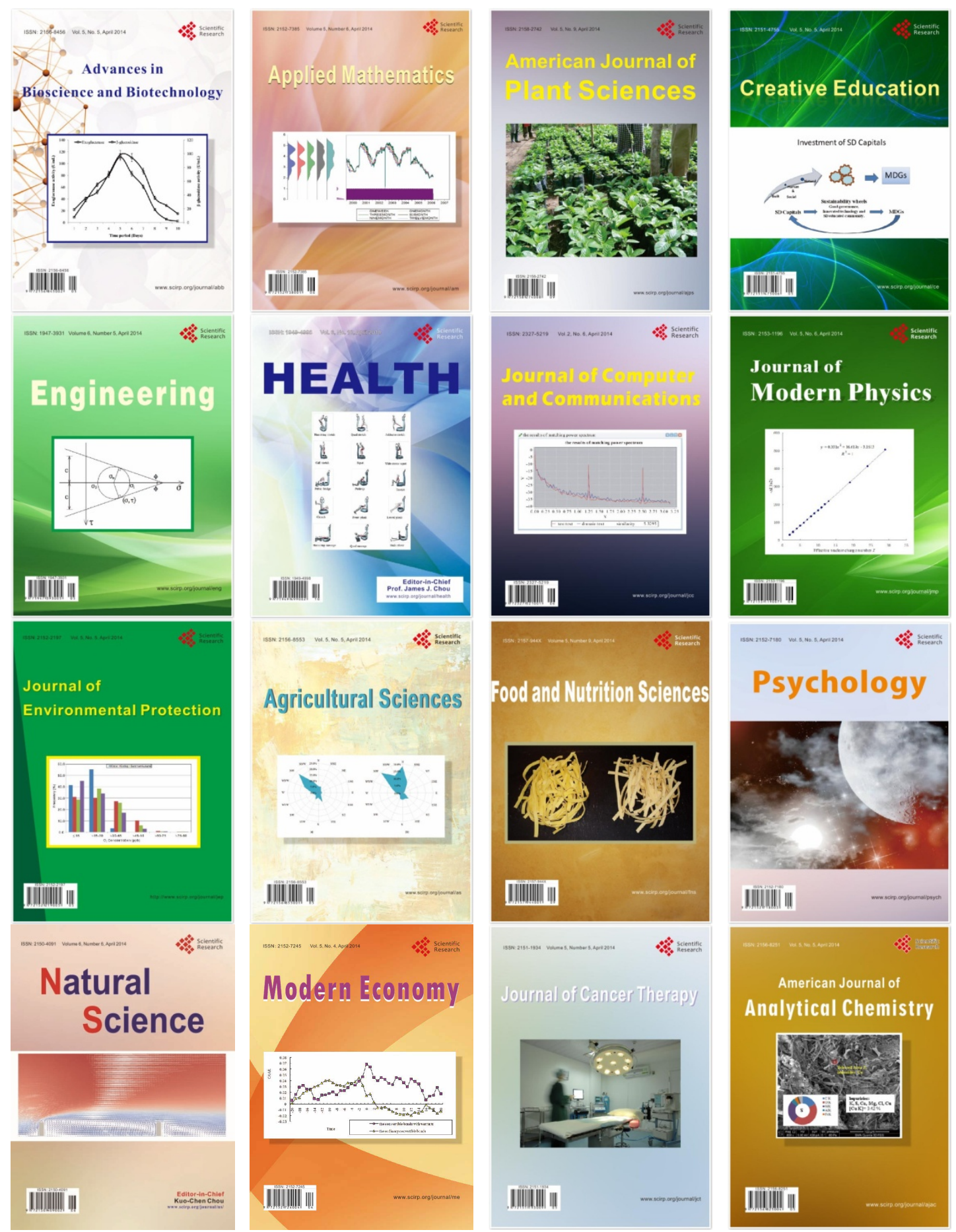